\title{
MODELO SOCIAL COMO ALTERNATIVA PARA EL DESARROLLO DE LA PERSONA CON DISCAPACIDAD, CALLAO. PERÚ
}

\author{
Social model as an alternative to the development of the person with \\ disabilities, Callao. Perú
}

\section{Felix David Garay Ordoñez* y Irma Milagros Carhuancho Mendoza**}

\section{RESUMEN}

Las personas con discapacidad tienen que lidiar diariamente con barreras físicas, de actitud, sociales y políticas, en vista que su desarrollo integral se encuentra limitada. El objetivo del presente trabajo es analizar la importancia del modelo social como alternativa para el desarrollo de la persona con discapacidad, Callao, Perú. La metodología empleada fue de enfoque cualitativo, método estudio de caso, la técnica utilizada fue la entrevista con su respectiva guía, tenemos además que coexistieron como unidades informantes: un funcionario del Estado de la Oficina municipal de atención a la persona con discapacidad (Omaped) Municipalidad Provincial del Callao, una ex coordinadora regional del Consejo para la integración de la persona con discapacidad (Conadis) Callao, cuatro personas con diferentes tipos de discapacidad y dos personas sin discapacidad. El procesamiento de datos se realizó mediante el Programa de análisis cualitativo Atlas Ti-7. De esta manera, se procedió con la triangulación de las teorías relacionadas y los trabajos previos, resultando de esta manera que los estudios guardaban coherencia con la investigación. Cabe precisar que autores multidisciplinarios como Abberley (1987), Oliver (1998) y Palacios (2008) fundamentaron un modelo social como el que se plantea. En la Convención sobre los derechos de la persona con discapacidad CDPD (ONU, 2006), se reconoció a estas personas como sujetos de Derechos Humanos. Actualmente existen avances en el Estado y la sociedad respecto al trato digno, accesibilidad universal e inclusión de la persona con discapacidad, pero las barreras aún subsisten, más aún porque las autoridades no cumplen con la normatividad para lograr una mejor calidad de vida. Por lo tanto, es necesario precisar que las políticas públicas sustentadas en el modelo social constituirían una alternativa para el desarrollo de la persona con discapacidad.

\footnotetext{
* Magíster en Gestión Pública; Doctorando en Gestión Pública y Gobernabilidad, Universidad César Vallejo, Lima - Perú; correo electrónico: fgaray64@ hotmail.com; ORCID 0000-0002-0570-3544

${ }^{* *}$ Doctora en Administración, Universidad César Vallejo, Lima - Perú; correo electrónico: irmamilagros@ yahoo.com; ORCID 0000-0002-4060-5667
}

681 
Modelo social como alternativa para el desarrollo de la persona con discapacidad, Callao. Perú

Palabras claves: Modelo social, persona con discapacidad, trato digno, accesibilidad, inclusión.

RECIBIDO: Mayo 2019

ACEPTADO: Julio 2019

\begin{abstract}
People with disabilities have to deal daily with physical, attitude, social and political barriers, since their integral development is limited. The objective of this paper is to analyze the importance of the social model as an alternative for the development of the person with disability, Callao, Peru. The methodology used was a qualitative approach, case study method, the technique used was the interview with their respective guide, we have also coexisted as reporting units: a State official of the Municipal office of attention to the person with disabilities Omaped Provincial Municipality of Callao, a former regional coordinator of the Council for the integration of the person with disabilities Conadis Callao, four people with different types of disability and two people without disabilities. Data processing was carried out through the Atlas Ti-7 qualitative analysis program. In this way, we proceeded with the triangulation of the related theories and the previous works, resulting in that the studies were consistent with the investigation. It should be noted that multidisciplinary authors such as Abberley (1987), Oliver (1998) and Palacios (2008) founded a social model like the one proposed. In the Convention on the Rights of Persons with Disabilities CDPD (UN, 2006), these persons were recognized as subjects of Human Rights. Currently there are advances in the State and society regarding the dignified treatment, universal accessibility and inclusion of the person with disability, but the barriers still exist, even more because the authorities do not comply with the regulations to achieve a better quality of life. Therefore, it is necessary to specify that public policies based on the social model would constitute an alternative for the development of the person with disability.
\end{abstract}

Keywords: Social model, person with a disability, dignified treatment, accessibility, inclusion.

\title{
Introducción
}

Históricamente las culturas antiguas, como Esparta, creyeron que las personas que mostraban alguna forma de discapacidad tenían que ser sujetos de infanticidio o exterminio, decían que era castigo de los dioses que tengan alguna forma de discapacidad (Palacios, 2008). Al trascurrir los años las personas con alguna discapacidad no fueron exterminadas, pero eran objeto de marginación y las ubicaban con los mendigos y enfermos. En la edad moderna, después de dos guerras mundiales; otras en Corea, y Vietnam, la discapacidad era considerada solo como un asunto médico 


\section{Felix Garay Ordoñez y Irma Carhuancho Mendoza}

Telos Vol. 21, No. 3 (2019). 681-709

y rehabilitador, a la persona con algún tipo de discapacidad se les asistía y/o rehabilitaba, es decir "normalizaba" a través de un tratamiento. En estos tiempos, el modelo social de discapacidad, ha tratado de concientizar sobre

la tenencia y cumplimiento de derechos de la persona con discapacidad (Pcd), y establece que ellas no pueden desarrollarse y tener oportunidades como los demás, porque la sociedad no provee, ni se adecúa para cubrir sus necesidades (Palacios, Romañach 2006; Padilla-Muñoz 2010).

La Organización Mundial de la Salud (OMS), basándose en el modelo social de discapacidad, manifiesta que la persona con alguna discapacidad es la que tiene carencia o inconveniente en su actividad, algún condicionamiento en su participación, que resulta entre, sus interacciones complejas por su condición de salud, su situación personal, y su amplio entorno en que vive y se desenvuelve. Por lo tanto, es necesario precisar que no se puede tratar a todas las personas con discapacidad de un mismo modo - existe discapacidad física, sensorial, intelectual y psíquica - individualmente esas personas interactúan de diversas maneras con su entorno (OMS, 2001).

Chan (2011), reporta que en el mundo hay más de 1,000 millones de personas con alguna forma de discapacidad, esto equivale al quince por ciento de la población del mundo, por país está entre el 10 y $15 \%$ de su población, dependiendo de su desarrollo y atención a la problemática.

Así también, en un futuro no muy lejano, habrá más personas que tendrán algún tipo de discapacidad en el mundo, esto es preocupante porque hay un incremento año a año. La población mundial tiene cada vez más ancianos, esto, debido a los mejores cuidados, avances en salud y mejor condición de vida a nivel general, pero esto no evita a estar propensos a alguna discapacidad originado por la propia edad. A nivel mundial se evidencia el incremento de las enfermedades consideradas crónicas, como son la diabetes, enfermedades del corazón, cáncer, alteraciones de la salud mental, entre otras; también influyen en esta predicción los factores ambientales, los accidentes vehiculares, 
Modelo social como alternativa para el desarrollo de la persona con discapacidad, Callao. Perú

las devastaciones causadas por la propia naturaleza, las contiendas armadas, guerras, las costumbres alimenticias y el consumo de productos nocivos como las drogas (Chan, 2011).

En países como Australia, Irlanda, Corea del Sur, las personas con discapacidad tienen menos oportunidades en el aspecto educativo y laboral, además que tienen el doble de probabilidades de ser más pobres que otras personas sin discapacidad. Asimismo, según el estudio realizado en Reino Unido, los hogares donde había personas con discapacidad acrecentaban los gastos del hogar y la tasa de pobreza ascendía de un $22 \%$ a un $44 \%$. Por otro lado, en los países en vía de desarrollo no sucedió lo mismo, puesto que en algunos la tasa de pobreza creció en menor porcentaje, porque se otorgaron subsidios por discapacidad (Uruguay, Chile, Panamá); en otros países aumentó grandemente de un $10 \%$ a un $20 \%$ hasta a un $30 \%$ (Vietnam, BosniaHerzegovina). En ambos grupos la discapacidad influye en la economía del hogar. Asimismo, corresponde señalar que en dicho Informe se sostuvo, que es al Estado y a la sociedad a quienes les corresponde asumir responsabilidades para revertir esta situación (OMS, 2011).

Estudios internacionales como el de Sánchez (2015), establece que la visión y misión institucional con ideales de una educación inclusiva favorecen a todo el alumnado. Además, la visión y misión se traduce en un compromiso decidido del profesorado en prácticas escolares inclusivas. El ser y la identidad institucional inclusiva conlleva a una convicción sólida, de modo que los docentes nuevos también asumen estos retos y tareas.

Igualmente, Otano (2015), expresa que, el enfoque de capacidades en el campo de la ética normativa, para alcanzar el desarrollo, busca favorecer la vida de aquellas personas que son más vulnerables dentro de una sociedad. La filosofía del bienestar y justicia social, con igualdad de oportunidades deben ser entendidas no solo de tener libertad de hacer, sino de poder hacer. 
Las diferentes normativas no son suficientes para conseguir la coordinación de una red de interés organizacional e individual para una investigación, se necesita de una visión compartida de los diferentes actores que tengan predisposición de resolver el problema y con ello trascienda en desarrollo social, además no se debe olvidar que en el caso de las personas con discapacidad serán definitivos los valores inclusivos ya afianzados en la institución (Sánchez, Romero y Padrón, 2019).

En el contexto peruano, en el año 2012 el Instituto Nacional de Estadística e Informática (INEI) llevó a cabo la I Encuesta Nacional Especializada sobre discapacidad (Enedis) los resultados mostraron que, las Personas con discapacidad a nivel nacional son 1'575,402 personas equivalente al 5.2\% de la población, resultados que son incongruentes con las cifras mundiales (10 a 15 por ciento), puesto que, en países más ricos y desarrollados que el Perú oscilaron entre el 10\% aproximadamente. Los resultados más resaltantes de esta encuesta fueron en los diferentes sectores los siguientes: en Educación $40 \%$ estudió primaria, 22.5\%, estudió secundaria y $11.4 \%$ estudió en instituto o universidad, o posgrado. En Salud el $92.4 \%$ no posee certificado de discapacidad, el 38.2\% no tiene un seguro, el $88 \%$ no recibe rehabilitación. Respecto al empleo el $76.8 \%$ no cuenta con ningún tipo de empleo, es una población económicamente inactiva; del $21.7 \%$ de la Población Económicamente Activa el 87.9\% tiene algún empleo (el $58.3 \%$ es trabajador independiente) y $12.1 \%$ está desocupada (INEI, 2014).

Las causas que contribuyeron a la problemática actual son los siguientes: Insensibilidad social, desconocimiento de las normas, favoritismo político en cargos donde se atiende a personas con discapacidad, falta de firmeza de las autoridades para la fiscalización, supervisión y control en la atención y derechos de las personas, todo ello tuvo como consecuencia las deficiencias notables en las entidades de atención a la persona con discapacidad, escaso progreso social, educativo, en salud, empleo y recreación. 
Modelo social como alternativa para el desarrollo de la persona con discapacidad, Callao. Perú

El Congreso de la República del Perú (1998) promulgó la primera Ley General de la Persona con discapacidad Ley 27050, que creó el Consejo Nacional para la Integración de las Personas con discapacidad (Conadis) Organismo rector de la discapacidad en el Perú. Esta misma Ley creó la Oficina Regional de Atención a las Personas con discapacidad (Oredis) en cada gobierno regional y la Oficina Municipal de Atención a las Personas con discapacidad (Omaped) en cada municipio provincial y distrital. Estas entidades al igual que el Conadis, aún, no cumplen ni hacen cumplir los derechos de la Persona con discapacidad en todo el país.

Igualmente, el Congreso de la República del Perú (2012) por insistencia promulgó la Ley General de la Persona con discapacidad Ley 29973, basándose en la información de la Organización de las Naciones Unidas (ONU, 2006) Convención sobre los Derechos de la Persona con discapacidad (CDPD), la misma que se sustentó en el modelo social de discapacidad; asimismo, se creó también el Sistema Nacional para la integración de la Persona con discapacidad (Sinapedis) incorporando a las Oredis y las Omaped.

Existe legislación, instituciones y personas encargadas para la atención de la persona con discapacidad en el Perú, pero se carece de capacitación, comunicación y coordinación entre ellas, para una buena toma de decisiones. Una forma de que estas instituciones y todos los que se encuentren involucrados dirijan su voluntad en una sola dirección, es desarrollar y ejecutar un Plan de desarrollo concertado para Cercado del Callao, basado en el modelo social de discapacidad; con esta herramienta se lograría una mayor y mejor atención a la persona con discapacidad, se crearían oficinas de documentación y centros de investigación que ayudarían a una efectiva inclusión; he aquí el objetivo de este estudio, el análisis del modelo social de discapacidad como alternativa para el desarrollo de la persona con discapacidad.

En el Callao existen más de 30 asociaciones de personas con discapacidad, esta atomización hace que estas organizaciones no tengan fuerza ante las diferentes autoridades regional y local, por lo que las autoridades conforme lo manifestaron en las 


\section{Felix Garay Ordoñez y Irma Carhuancho Mendoza}

Telos Vol. 21, No. 3 (2019). 681-709

entrevistas efectuadas, hacen lo que pueden, tampoco tienen empatía para suplir las necesidades de la persona con discapacidad; situación que puede revertirse. El Estado y la sociedad en el Callao aún no proporcionan las facilidades que le permitan a una persona con discapacidad tener equiparación de las mismas oportunidades que poseen las personas que no tienen alguna discapacidad.

Según estudio realizado por Cohaila (2015) manifiesta que, en el distrito de Los Olivos, se observa satisfacción de los servicios brindados por su municipio, mayor nivel de mecanismos de inclusión, pertenencia y reconocimiento, mayor confianza en el gobierno local de todos sus pobladores; pero, en el distrito de San Martín de Porres sigue habiendo un conjunto de necesidades, requerimientos y problemáticas diferentes, teniendo la gestión municipal que priorizar la atención a los ciudadanos con discapacidad. Estos acontecimientos se basan en la Teoría del Derecho Natural de Thomassio: puesto que, el principio primordial de este derecho consiste en la existencia de la felicidad de la persona y lo podrá hacer teniendo una vida honesta, digna y justa honestum, decorum, iustum -, por consiguiente, podemos concluir que el Estado es el producto de un contrato inspirado en consideraciones utilitarias (Misari, 2013).

En este contexto, es pertinente hablar de la teoría Social de discapacidad, el británico Abberley (1987), afirma que había opresión, se vivía sin consideración porque veían a la persona con discapacidad como un simple habitante y no como ciudadano con derechos, y lo excluían de su participación en la diversidad de actividades de la sociedad.

Así también la Psicología Positiva de Seligman (2000), expuso que a nivel grupo, trata de las virtudes cívicas y las instituciones en que se impulsan los individuos hacia una mejor ciudadanía: responsabilidad, altruismo, cortesía, moderación, tolerancia y ética de trabajo.

Estas teorías se relacionan con las personas con discapacidad, para que ellas no sean vistas como marginadas, como objetos, o invisibles, sino por el contrario como 
Modelo social como alternativa para el desarrollo de la persona con discapacidad, Callao. Perú

personas con derechos, sentimientos, emociones tan igual como cualquier persona en la sociedad, y que precisa de un trato especializado para lograr la atención y solución de sus problemas por parte del Estado y la sociedad.

El Conadis a nivel nacional, la Oredis y la Omaped a nivel regional y local de la Provincia Constitucional del Callao respectivamente, son las instituciones del Estado llamadas a alcanzar la inclusión de todas las personas con discapacidad, por ende, lograr su desarrollo en todo aspecto. El presente estudio, luego de dar a conocer el modelo social de discapacidad como alternativa, pretende la realización de un plan de desarrollo para el Callao, y convertirse en el distrito pionero en aplicar un piloto basado en este modelo y lograr el desarrollo de las personas con discapacidad, eliminando todas las barreras que le niegan su progreso y plena inclusión.

El presente artículo se ha elaborado en cinco secciones, la primera, se refiere al Resumen y Summary; la segunda está referida a la introducción; la tercera es el cuerpo, que consta de teoría referente al tema, la metodología empleada, los resultados y la discusión; en la cuarta se mencionan las conclusiones y por último en la quinta las referencias bibliográficas.

\section{Modelos de tratamiento de la discapacidad}

Para tener conocimiento más amplio de la ubicación y contexto del modelo social se mencionarán algunos modelos anteriores en el tiempo, para el tratamiento de la discapacidad.

El modelo de prescindencia consideró que si una persona tenía alguna discapacidad era por motivos religiosos, y que ella era un lastre para la familia y comunidad. Protágoras (1998), señaló: “...pero los vástagos de los inferiores, o de los superiores cuando hayan nacido deformes, serán rechazados...” (p. 28). Esta sentencia hizo que se cometiera infanticidio en la antigua Grecia.

Antiguamente en Grecia las personas con malformaciones o debilidades (físicas) notorias eran entregadas para sacrificio a sus dioses; no se sabe, si esto, era un 
privilegio o una forma drástica de exclusión (infanticidio, genocidio) de la sociedad de estas personas (Padilla-Muñoz, 2010).

Este Modelo, muestra dos particularidades importantes, la creencia en lo maligno y divino que es la causa de la discapacidad, y que una persona con alguna discapacidad es inútil, no pudiendo realizar ningún aporte a la sociedad; este modelo en su submodelo eugenésico: desecha la vida de la persona con alguna discapacidad, cometiéndose infanticidio y genocidio; en su sub modelo de marginación: se prescinde de ellas a través de la exclusión (Palacios, 2008). En la historia de la civilización humana se realizaron estas acciones para mejorar la raza, por ejemplo, en la Grecia antigua y el holocausto nazi (Villela y Linares, 2011).

El submodelo de marginación, se sitúa mayormente en la Edad Media, a la persona con alguna discapacidad se la ubica con los más pobres, los mendigos y los excluidos, se les subestima y se les tiene compasión, se dejó de lado el infanticidio y genocidio, pero los niños y niñas que tenían alguna discapacidad fallecían por falta de atenciones primordiales por su edad, los que sobrevivían, sólo les quedaba la caridad, mendigar, y ser sujetos de mofa y distracción para los demás (Palacios, 2008).

En cuanto al tratamiento de la persona con discapacidad, este constituye el más trágico de los modelos y que duró muchos años, puesto que, las personas fueron asesinadas o fueron excluidas sin compasión alguna.

El modelo rehabilitador o modelo médico, refiere que, la discapacidad, ya no es una condena de los dioses, sino que es una anormalidad física, psíquica o sensorial, pudiendo ser de nacimiento o adquirida, y la sitúa por debajo de unos niveles que son considerados normales. El modelo rehabilitador o médico tuvo dos características importantes; primero, lo que produce o causa discapacidad no es por creencia religiosa, sino científicas, se habla de salud o enfermedad; segundo, la persona con discapacidad no es considerada inútil o carga, puede aportar, pero si es rehabilitada o normalizada (Palacios, 2008). 
Modelo social como alternativa para el desarrollo de la persona con discapacidad, Callao. Perú

Las barreras (de actitud, sociales, políticas, físicas) deciden quienes son incapaces o ineficientes - así está diseñada generalmente la sociedad - determinan quien puede participar y quien no en los diversos ámbitos de la sociedad, qué es un cuerpo sano y otro enfermo; por esto, se trata de curar, normalizar a una persona con alguna discapacidad, esto es, causa de injusticia y desigualdades (Venturiello, 2017).

Según este modelo, la discapacidad es médico-científica, es enfermedad propia de la persona, la persona con alguna discapacidad puede contribuir a la sociedad solo si ha sido tratada (rehabilitación y normalización), es decir, hacer que se asemeje lo mejor que se pueda a una persona normal, de tal forma que la sociedad los valore como personas y ciudadanos. En este modelo, no se habla de la sociedad como causante de discapacidad, se subestima la capacidad y contribución de una persona con alguna discapacidad en la sociedad; el trato social es asistencialista, paternalista y caritativo.

El modelo de diversidad funcional, señala que la persona con discapacidad, se desenvuelve y actúa de forma diversa o singular que las demás personas de su comunidad y considera que esta diferencia o diversidad funcional no es tomada en cuenta, produciéndose la falta de respeto de las mayorías (Palacios y Romañach, 2006).

El crear cultura inclusiva en una comunidad está ligada directamente a que todos sus miembros valoren y acepten la diversidad funcional de las personas con discapacidad. Teniendo esta comunidad una cultura inclusiva como forma de vida, desarrollará buenas políticas y buenas prácticas en su quehacer diario y en el trato hacia la persona con alguna discapacidad, significando que se puedan transmitir estos valores a nuevos integrantes de la comunidad (Booth y Ainscow, 2011).

Este modelo, tiene un enfoque más radical, propone eliminar la línea divisoria entre "normalidad" y "discapacidad", es decir veta todo el concepto de "normalidad" física, sensorial o mental. El fundamento del concepto de diversidad funcional señala la eliminación completa de cualquier noción de diferencia o desviación; de lo contrario bastaría con quitar las etiquetas de discapacitados y no discapacitados, a diversos y no diversos (Palacios y Romañach, 2006). Cada uno de nosotros tiene desarrollada alguna 


\section{Felix Garay Ordoñez y Irma Carhuancho Mendoza}

Telos Vol. 21, No. 3 (2019). 681-709

capacidad para funcionar en diferentes momentos y situaciones. Muchas actividades implican el funcionamiento de varias maneras. Por ejemplo, los atletas de élite necesitan para funcionar una muy alta capacidad física y cognitiva, esto no significa que los que no se desenvuelven como ellos tienen discapacidad. Otro ejemplo son los científicos, que necesitan de una alta capacidad cognitiva para alcanzar un buen desempeño, tampoco representa que los que no llegan a ese nivel cognitivo son discapacitados (Patston, 2007).

El Modelo social de discapacidad, un modelo social idóneo, tiene como objetivo que la persona pueda vivir por muchos años y de la mejor manera, además de ostentar una vida social amplia y organizada, para satisfacer las necesidades humanas. Lo importante de un modelo social es como se implementa y ejecuta, son las mismas personas que frustran el modelo. Si queremos que un modelo social sea eficiente en atender a los requerimientos importantes de las personas, este modelo ha de ser concordado y coordinado entre las diferentes organizaciones y el Estado.

En los noventa; se planteaba que, de las vivencias diarias y propias de la persona con discapacidad, se debía tomar el tratamiento que se les daría, así también, las acciones sociales y políticas debían ser propuestas por ellos, y los servicios se realizarían conforme a esta nueva realidad creada por ellos mismos, para satisfacer sus necesidades (Oliver, 1998).

Priestly (1998), sugiere una comprensión adecuada de la teoría de la discapacidad y una distinción entre los enfoques de modelos sociales e individuales. El modelo social de discapacidad busca en la sociedad, que una persona con discapacidad (deficiencia física o intelectual), limitación o restricción que tenga, aporte al desarrollo social y económico. Se eligió el modelo social porque es el indicado para que, por fin, se eliminen las barreras que impiden desarrollarse a la persona con discapacidad.

Posteriormente, a la eliminación de la gran mayoría de barreras, se podría pensar en otro modelo como el mencionado modelo de diversidad funcional, pues las 
Modelo social como alternativa para el desarrollo de la persona con discapacidad, Callao. Perú

personas con discapacidad podrán desenvolverse lo más independiente posible para desarrollarse.

Otro aspecto fundamental que busca el modelo social de discapacidad, es que, se distinga que la discapacidad no es el problema, es la sociedad que al mantener las diferentes barreras no puede ofrecer plena accesibilidad, ni servicios adecuados o acondicionados para cubrir sus requerimientos mínimos e importantes como cualquier otra persona. Se debe realizar verdaderos cambios para que la sociedad en general los acepte como son y los incluya como personas que tienen mucho que ofrecer (Maldonado, 2013).

Los médicos y científicos deben continuar con sus avances y facilitar los medios para mejorar su salud y rehabilitarlas, funciones que son propias de su especialidad médica. Pero la búsqueda de la equidad para igualar las oportunidades con los demás, corresponde al Estado y a la sociedad.

Considerado el padre del modelo social de discapacidad Oliver (1998) es el primero en llamar de esa manera a la teoría social existente y aclaró los conceptos de deficiencia y discapacidad; señaló, que la discapacidad tiene que ser planteada como un todo. Las barreras que menciona son las de actitud, físicas, sociales y políticas (señala la falta de acceso a instalaciones públicas y privadas, a una educación inclusiva, a redes de información y comunicación, al empleo, al derecho de movilizarse distancias largas y casas accesibles).

En el campo socio-político el modelo social de discapacidad ha evolucionado del antiguo modelo de prescindencia y el modelo médico o rehabilitador, proponiendo que, para el desarrollo de la persona con discapacidad en Cercado del Callao, se debe eliminar la mayor cantidad de barreras (actitud, físicas, sociales y políticas) en favor de las personas con alguna discapacidad (física, intelectual y sensorial).

Para la implementación de este modelo el Estado mediante programas y políticas públicas está llamado a sensibilizar, concientizar, dar accesibilidad universal, facilidades y oportunidades, en todo aspecto, a la persona con discapacidad a través de 
un consenso (modelo social); busca el cambio de actitud de la sociedad hacia la persona con discapacidad, con el fin de eliminar las barreras CDPD (ONU, 2006).

En el Perú se han dado dos leyes para las personas con discapacidad, la última data del año 2012, la misma que está basada en el modelo social, donde propone la eliminación de las barreras y el desarrollo de la persona con discapacidad.

En el campo de la salud el modelo biomédico aplicado por muchísimos años (subsiste hasta hoy) mediante la dicotomía mente - cuerpo, refería que la enfermedad era un problema exclusivamente patofisiológico y su curación se realiza a través de la biología (Laham, 2017). Engel (Psiquiatra norteamericano) en 1977 defendió un nuevo modelo médico holístico (lo llamó biopsicosocial) en reemplazo del antiguo modelo biomédico, esta propuesta tuvo aceptación por quienes querían que la empatía y compasión se incluya en las prácticas médicas (Borrell i Carrió, 2002). La OMS y la Organización Panamericana de la Salud OPS denominaron como modelo biopsicosocial para la atención de la persona con discapacidad (centrado en la rehabilitación), al tratamiento y rehabilitación no sólo médico, sino, también social y multidisciplinario. Cabe precisar que este modelo también se aplica en Psiquiatría, así como, en casos de esquizofrenia, adicciones y salud mental. Teóricamente, el Modelo Biopsicosocial intentó generalizar que la dolencia y la enfermedad están afectados por los niveles de articulación humana que van desde el molecular hasta el social (Tizón, 2007).

En tal sentido, el modelo biopsicosocial busca integrar a la persona desde el aspecto de salud, mientras que el modelo social busca su inclusión desde lo político y social, en consecuencia, una persona puede estar integrada, pero no incluida, son dos términos diferentes, por ejemplo: Digamos que una persona vive en un distrito, transita por sus calles, usa los servicios que brindan las instituciones públicas y privadas con acceso público y realiza otras actividades más con normalidad. En cambio, si esta es una persona con discapacidad, tiene derecho a todo lo antes mencionado e integra este distrito; pero, si no hay una vivienda adecuada, si las calles y veredas no le permiten el 
Modelo social como alternativa para el desarrollo de la persona con discapacidad, Callao. Perú

libre tránsito, si no tiene acceso a los servicios por falta de personas que conozcan del lenguaje de señas, si para el acceso a estos servicios no hay rampas o ascensores, si recibe miradas intimidadoras o la subestiman, se puede afirmar que esta persona con discapacidad no está incluida en ese distrito.

Comparando ambos modelos, social y biopsicosocial tenemos que, el modelo social tiene como antecedentes el modelo de prescindencia y el médico o rehabilitador, pertenece al aspecto político- social, considera a la persona con discapacidad como ciudadano sujeto de derechos, se implementa mediante programas y políticas públicas para normalizar a la sociedad. El modelo biopsicosocial, tiene como antecedente el modelo biomédico que aún subsiste, pertenece al aspecto de salud (rehabilitación), considera a la persona con discapacidad como paciente, busca multidisciplinariamente su rehabilitación integral, incluyendo la Psicología, lo social y ambiente, es muy positivo en su área.

Todo modelo es teórico, puede funcionar muy bien en un lugar, medianamente en otro espacio y mal en otro, por lo tanto, es relativo, depende de muchos factores; en este sentido, se espera que el modelo social como alternativa para el desarrollo de las personas con discapacidad, sea óptimo en el Callao.

Para el presente estudio se consideró como primera categoría: el Modelo social de discapacidad y se busca con este modelo que una persona con discapacidad que cuente con alguna deficiencia, limitación o restricción, pueda desenvolverse lo más independientemente posible en su entorno, y realizar funciones básicas para su desarrollo como cualquier persona, con respecto a salud, educación, empleo y recreación; no considerándose disminuida, sintiéndose parte activa en la sociedad con las mismas oportunidades que todos.

El modelo social propone se elimine todo tipo de barreras para el desenvolvimiento de la persona con discapacidad, estas son:

- Barreras de actitud (Estereotipo, Estigma, Prejuicio y Discriminación), las barreras de actitud llamadas así por el comportamiento dirigido hacia la persona con 


\section{Felix Garay Ordoñez y Irma Carhuancho Mendoza}

Telos Vol. 21, No. 3 (2019). 681-709

discapacidad, son las más importantes a ser eliminadas porque hacen que se presenten otras barreras. No permiten conocer y valorar la enorme dificultad que significa para una persona con discapacidad trasladarse distancias largas, ingresar a los establecimientos sin accesibilidad, los obstáculos para su atención en salud, educación, empleo, recreación (CDC, 2017).

El CDC (2017), señala que, muchas personas estereotipan, a la persona con discapacidad, asumiendo que su modo de vivir y bienestar es deficiente, creen que tienen alguna enfermedad. En cuanto a prejuicio, estigma y discriminación dice que, estas actitudes provienen de las ideas de las personas que ven la discapacidad como una desventura de la persona, que tiene una sanción que pagar o que no sabe conducirse dentro de su comunidad.

- Barreras sociales (Exclusión social, salud, educación, empleo y recreación) en la Declaración Universal de Derechos Humanos (ONU, 2015) se afirma, todos los seres humanos nacen libres e iguales en dignidad y derechos. Sin embargo, han pasado más de 70 años y existen cerca de mil millones de personas con discapacidad cuyos derechos humanos están limitados o totalmente negados. En cualquier lugar del mundo, en todos los niveles sociales, existen personas con discapacidad, está clara la necesidad de actuar.

En un documento conjunto de la Organización de las Naciones Unidas para la Educación, la Ciencia y la Cultura, la Organización Internacional del Trabajo, y la Organización Mundial de Salud llamado Estrategia para la rehabilitación, la igualdad de oportunidades, la reducción de la pobreza y la integración social de las personas con discapacidad, refiere, que la problemática de la discapacidad con el aporte de la Convención sobre los derechos de la Persona con discapacidad, ya no se ve en el mundo solo por su limitación. En la psique de muchas personas, ahora se tienen conceptos más amplios, está que, si no hay intervención de la persona con discapacidad con "actividades" y "participación" en la sociedad se propicia la discapacidad. Según, este 
Modelo social como alternativa para el desarrollo de la persona con discapacidad, Callao. Perú

documento conjunto, aún, no hay país en el mundo que haya eliminado por completo las barreras físicas o arquitectónicas, ambientales y sociales que causan o producen discapacidad, pero, se está en ese camino. (Unesco, OIT y OMS, 2005)

- Barreras físicas (Inaccesibilidad física e Inaccesibilidad en comunicación). El CDC (2017) indica que, una de las principales barreras para una persona con discapacidad son las físicas, por la inaccesibilidad arquitectónica que impiden o bloquean el traslado o tránsito libre y el ingreso a algún lugar.

La OMS (2011), señala las barreras físicas como inaccesibilidad. Las edificaciones, el transporte y las comunicaciones no se allanan para el acceso de la persona con discapacidad. Uno de los importantes accesos que debe tener es el transporte, porque sin movilidad no se pueden trasladar a los centros de salud, al lugar de empleo, de educación o recreación; esto hace que no participen en actividades propias y comunes de la sociedad. En comunicación personal, las personas sordas son a menudo las que tienen mayores problemas en su atención, no hay muchas personas que estén capacitadas en lenguaje de señas.

En el Perú, es común esta inaccesibilidad de comunicación, sólo el canal del Estado cumple en presentar a un intérprete de lenguaje de señas cuando se trasmiten noticias u otros programas. Una persona con discapacidad, en cuanto al acceso que tienen a las tecnologías de información y comunicación TIC, es muy bajo, inclusive no pueden acceder a beneficios tan simples como un teléfono, internet o televisión.

$\mathrm{Si}$, por lo contrario, se tuviera acceso mejoraría la calidad de vida de las personas con discapacidad, en la presente investigación accesibilidad se refiere al fácil acceso al entorno o ambiente que son: al libre tránsito por calles y veredas, a las edificaciones sean públicas o privadas, a los medios de transporte para estudiar, trabajar, atenderse en algún establecimiento de salud, o simplemente recrearse; al uso de las tecnologías de información y comunicación (escrita, hablada, televisiva, teléfono, internet, entre otros), al uso de los servicios públicos y privados de atención al público, y otros. Es por todo esto que, desde el modelo social se busca se eliminen las barreras 
que impidan la autonomía, desenvolvimiento y participación de la persona con discapacidad, por el principio de igualdad de oportunidades para todos.

Alonso (2016), cita a Kovacs quien erigió el concepto de accesibilidad separando de manera sencilla los conceptos técnicos, del objetivo que busca la inclusión de la persona con discapacidad, señalando, accesibilidad, es el acceso físico y de comunicación relativo a un edificio, vivienda, transporte y tránsito (incluyendo aceras y cruces), sitios web u ordenadores, e información. Incluye las aproximaciones y estándares utilizados para permitir un fácil acceso a los equipamientos por parte de las personas con discapacidad.

- Barreras políticas (Falta de voluntad política e Incumplimiento de normas), el CDC (2017) refiere que, las barreras políticas se dan por la falta de concientización (sensibilidad social) de las autoridades para cumplir y hacer cumplir las normas, a fin, de exigir que los planes y las respectivas acciones de estos, creen accesibilidad universal.

Las barreras políticas también pueden constituir: negar a las personas con discapacidad, intervenir en las actividades en general de la sociedad y favorecerse de los planes de atención del Estado; así también negar el acceso al empleo o de participación, porque se lo impide las barreras físicas; asimismo negarle realizar ajustes razonables, a fin, de que pueda acceder al empleo para el que postuló o fue contratado para realizar, habiendo cumplido con los requisitos.

Una nueva política social, debe suprimir cualquier tipo de exclusión; las políticas públicas, la educación, organizaciones y sociedad tienen que lograr un cambio radical, y así, alcanzar el éxito en políticas de inclusión, con la visión de producir un auge en el desarrollo de la Persona con discapacidad.

La segunda categoría en el presente estudio fue:

Desarrollo de la persona con discapacidad, siendo la discapacidad cualquier deficiencia, limitación y restricción de la participación de una persona, revirtiendo esta 
Modelo social como alternativa para el desarrollo de la persona con discapacidad, Callao. Perú

situación lo más que se pueda con políticas públicas acordes a sus necesidades, la persona con discapacidad podrá lograr empoderarse, aumentar su autoestima y alcanzar liderazgo dentro de la sociedad, así obtendrá una buena calidad de vida, ejerciendo sus derechos y funcionamientos, teniendo la capacidad de elegir y disfrutar lo que más anhela (concepto propio)

- Desarrollo de capacidades (Empoderamiento, Autoestima y Liderazgo), una persona con discapacidad es parte de una familia, la familia es parte de la sociedad, la sociedad conforma el Estado Peruano; he aquí la importancia de una verdadera inclusión de la persona con discapacidad; ellos tienen necesidades, sueños, metas a conseguir como persona, como parte de una familia, como parte de la sociedad, es así de fácil apreciar la importancia de lograr su desarrollo, pues, esto implica desarrollar nuestro propio Estado Peruano.

El Programa de las Naciones Unidas para el Desarrollo (ONU, 2009) indica que, el desarrollo de capacidades se refiere a grandes cambios que empoderen a las personas, los líderes, las organizaciones y las sociedades. Este concepto deriva que, empoderando a la persona con discapacidad, sus líderes y a sus instituciones, se tiene como consecuencia un empoderamiento de la sociedad en su conjunto; esto aún, no es entendido por la mayoría de las autoridades.

Desarrollar las capacidades radica en aumentar algunas condiciones - mejor desempeño, lograr valor añadido, fomentar nuevo talento - en el lugar donde interactúan, para que apliquen toda su capacidad (Rueda, 2013). El concepto al trasladarlo al entorno, al ambiente en donde interactúa la persona con discapacidad, por la subsistencia de las diferentes barreras no puede desarrollarse, ni mostrar lo que son capaces, ni demostrar todo su potencial.

Una alta autoestima predice de forma prospectiva el éxito y el bienestar en los dominios de la vida tales como las relaciones, el trabajo y la salud (Orth y Robins, 2014). De esta afirmación surge la importancia de buscar y conseguir que la persona con discapacidad logre su autoestima y hacer que la mantenga, es muy importante la 
autoestima en todas las personas, pero en una persona que ha adquirido discapacidad (enfermedad, accidente, secuelas) es más importante aún por los cambios que sufre y significa una nueva forma de ver la vida.

El liderazgo es clave para crear, gestionar y cambiar la cultura; los líderes diseñan, guían y enseñan; son los encargados de construir una organización o sociedad donde la gente siga expandiendo sus capacidades para comprender lo complejo de la realidad. La construcción de una visión compartida alienta un compromiso a largo plazo (Senge, 1990). Es cuestión de fomentar y buscar líderes entre las personas con discapacidad para que ellos desarrollen una nueva cultura y lograr así un nuevo Estado social inclusivo.

- Calidad de vida (Funcionamientos y Capacidades), la presente investigación examinó el enfoque de funcionamientos y capacidades, para repensar la concepción de desarrollo. El más importante impulsor de este enfoque fue el experto en economía el hindú Amartya K. Sen, premio nobel de economía 1998, obteniendo su pensamiento respecto a funcionamientos y capacidades para evaluar la calidad de vida. El peso de su enfoque incide en los estudios sobre desarrollo, su concepto de desarrollo y sus fundamentos teóricos, inclusive el PNUD tomó sus conceptos para llevar a cabo la evaluación y calificación de los países para ver su desarrollo.

El enfoque de Amartya Sen con respecto a la calidad de vida, está primero, en los funcionamientos (habilidad de una persona para hacer actos valiosos) y la capacidad (combinaciones alternativas que una persona puede lograr); queda claro la diferencia ante la antigua medición de suplir necesidades básicas como Calidad de vida; segundo, las capacidades como fundamentación teórica del concepto de desarrollo humano, se vincula a la economía del bienestar y a la teoría de la elección social. Con este enfoque se trata de evaluación, valoración de funcionamientos y capacidades que tiene que ver con elementos constitutivos de la persona y no con bienes o recursos primarios (Sen, 1987). 
Modelo social como alternativa para el desarrollo de la persona con discapacidad, Callao. Perú

Funcionamientos elementales (estar nutrido, tener buena salud) o más complejos (alcanzar la auto dignidad o incluirse socialmente). Cuando la satisfacción de vida se considera muy ligada a las posibilidades de tomar decisiones y elegir entre opciones diversas (capacidades), se abren oportunidades a la persona con discapacidad para expresar sus gustos, deseos, metas, aspiraciones, y a tener mayor participación en las decisiones que les afectan - inclusión -. (Sen, 1987). El desarrollo de un país, estado o ciudad, que acceda a este enfoque, se mide por como tratan a las personas vulnerables y qué calidad de vida le están brindando.

En España investigadores sobre discapacidad validaron la Escala y el Modelo teórico de Calidad de vida para personas con discapacidad intelectual, midiendo y evaluando la calidad de vida en un universo de 413 personas con ese tipo de discapacidad.

Consideraron para esa validación ocho dimensiones: Bienestar emocional, bienestar material, bienestar físico, relaciones interpersonales, inclusión social, desarrollo personal, autodeterminación y derechos (Schalock y Verdugo, 2007). España, es uno de los países que ha avanzado y transformado a sus autoridades y sociedad en general en el tratamiento de discapacidad y lo hizo con más énfasis luego de la Convención sobre los derechos de la persona con discapacidad (Álvarez, 2009). En el Perú con el modelo social, se quiere comenzar a recorrer el camino para una buena calidad de vida de las personas con discapacidad en general.

Una persona con discapacidad física teniendo accesibilidad arquitectónica total, es una persona con buena calidad de vida, y tendría las ocho dimensiones que señala Verdugo en su validación con puntaje alto (esto se señala en los resultados del presente trabajo), pero una persona con discapacidad sensorial (sordera) con accesibilidad arquitectónica total no gozará de una buena calidad de vida, su necesidad es diferente y está centrada más en la comunicación a través del uso de lenguaje de señas, y si hubiera personas que sepan lenguaje de señas a todo lugar donde vaya, estará muy feliz. Es por esto que, se ha tomado la teoría de funcionamientos y capacidades de 
Amartya Sen, para señalar una buena calidad de vida de las personas con discapacidad en general, implementando el modelo social en Cercado del Callao, que busca eliminar las barreras que aún persisten.

El bienestar personal deseado, está constituido por múltiples dimensiones centrales que son afectados por factores personales y ambientales. Estas dimensiones centrales son iguales para todas las personas, pero pueden variar individualmente por la importancia y valor que se les da. La valoración de las dimensiones está asentada en indicadores que son susceptibles a la cultura y al contexto en que se aplica (Schalock y Verdugo, 2007).

\section{Método}

Estudio de enfoque cualitativo, de diseño de estudio de caso; es una modalidad de búsqueda empírica que se adecúa para estudiar problemas prácticos o situaciones específicas (Ñaupas, Mejía, Novoa y Villagómez, 2014). Con la presente investigación se da a conocer el modelo social como alternativa, así como, la situación real de las personas con discapacidad en Cercado del Callao, sus necesidades y sus anhelos, a fin de que ellas puedan alcanzar su desarrollo.

Para la recopilación de datos se realizó a través de las entrevistas semiestructuradas con una duración de 30 a 50 minutos, quedando conformado por: a) Funcionario encargado de la Omaped de la Municipalidad Provincial del Callao; b) Ex coordinadora regional del Conadis Callao, se invitó a la suscrita porque durante el periodo de la investigación no se había nombrado a un representante en este cargo; igualmente, se invitó formalmente a 13 personas con discapacidad, de las cuáles cuatro respondieron voluntariamente para su participación, quedando entonces constituida por: 1ra discapacidad física (usuaria de silla de ruedas), 2da discapacidad sensorial invidente, 3ra discapacidad sensorial - sordera, 4ta discapacidad física (usuaria de silla de ruedas) de Carmen de la Legua-Reynoso. 
Modelo social como alternativa para el desarrollo de la persona con discapacidad, Callao. Perú

Asimismo, se revisó en todo el estudio la información sobre el modelo social de discapacidad desde la perspectiva de diversos autores, la Convención sobre los derechos de la persona con discapacidad (ONU, 2006) y Congreso de la República del Perú (2012) Ley General de la persona con discapacidad 29973 en el Perú.

Finalmente, para organizar toda la información y presentar los resultados se utilizó el software Atlas Ti 7. En todo momento durante la investigación se asumió los aspectos éticos correspondientes.

\section{Resultados}

Cada sociedad tiene en un tiempo determinado, un contexto social, en el cual instituye colectivamente lo apropiado y lo inapropiado, es decir, hacen la diferencia, existen a su vez unos expertos que determinan a través de juicios clasificatorios a los que presentan diferencias, proponen el vocabulario de cómo se les denominará, señalan el papel social que van a cumplir en su comunidad y el probable tratamiento que se les va a dar (Aguado, 1995). El modelo social es el llamado a brindar soluciones en este momento - contexto social - para desarrollar a la persona con discapacidad.

Para saber en qué áreas y como el modelo social a través de un Plan bien elaborado logrará eliminar todas las barreras, se tuvo que conocer cuáles son las barreras de actitud (estereotipo, estigma, prejuicio, discriminación), barreras físicas (inaccesibilidad física -incluyendo transporte- e inaccesibilidad en comunicación), barreras sociales (exclusión social, en salud, en educación, en empleo, en recreación), y barreras políticas (falta de voluntad política, incumplimiento de normas).

En base a las respuestas de los entrevistados sobre el modelo social, indicaron que a través de su aplicación, en primera instancia se suprime las barreras de actitud, con esto se logra que otras barreras como las físicas, sociales y políticas, sean eliminadas al cambiar la actitud hacia la persona con discapacidad; el trato hacia ellos se torna en digno y facilitador; se observó en sus respuestas que cuando reciben un buen trato sea en el banco, en el centro de salud u otro establecimiento, quedan contentos y 


\section{Felix Garay Ordoñez y Irma Carhuancho Mendoza}

Telos Vol. 21, No. 3 (2019). 681-709

motivados por la atención de esos lugares; asimismo, cuando se les participa en las diversas actividades de la sociedad sienten que se les está dando un trato digno.

El Congreso de la República del Perú (2012) en la Ley General de la Persona con discapacidad 29973 menciona que, la persona con alguna discapacidad tiene derecho a la accesibilidad universal y de comunicación y es el Estado quien garantiza estos derechos. Sin embargo, estos derechos no se cumplen como debería ser y persisten las barreras para el libre tránsito y acceso total. La falta de voluntad política e incumplimiento de normas (respuesta que más repiten los entrevistados en el presente estudio) son los impedimentos de las autoridades para realizar y supervisar adecuaciones del entorno arquitectónico. Los encargados de tomar decisiones al respecto, no están sensibilizados ni tienen ninguna empatía con la persona con discapacidad (Del Águila, 2011); por esto, sugieren los entrevistados, que personas con discapacidad calificadas deben asumir estos cargos por su empatía con esta problemática.

En la Omaped de la Municipalidad Provincial del Callao refiere el funcionario del Estado que de las 8 personas que laboran ahí, solo una, es persona con discapacidad, y no tiene poder de tomar decisiones. Esta situación, sustenta y ratifica el pedido para nombrar a personas con discapacidad calificadas en estos cargos. Por la desatención a la persona con discapacidad, algunos entrevistados señalaron que se ven en la necesidad de realizar marchas pacíficas de reclamo de sus derechos, porque, a través, de la presión social manifiestan, logran ser visibles y los obligan a cumplir con sus derechos.

A través, de la aplicación de un modelo social indican los entrevistados, se suprime las barreras políticas, y al eliminar esta se eliminarían las barreras físicas y sociales, puesto que, son las autoridades políticas las encargadas de las políticas públicas y de la supervisión del cumplimiento de las normas, definitivamente, las autoridades son las que ayudan o no al desarrollo de la persona con discapacidad y pueden involucrar y comprometer también a toda la sociedad; porque, las autoridades 
Modelo social como alternativa para el desarrollo de la persona con discapacidad, Callao. Perú

políticas tienen el poder de emplear coacción para que se cumpla con la ley en los diferentes ámbitos de la sociedad en transporte, empleo, educación, salud, recreación, y lograr la verdadera inclusión de todas las personas con discapacidad. En el presente estudio por las respuestas obtenidas, se apreció que el incumplimiento de normas se relaciona directamente con la falta de voluntad política de las autoridades.

Las personas con discapacidad entrevistadas manifiestan que, logrando la eliminación de todas las barreras, la persona con discapacidad es capaz de lograr el desarrollo de sus capacidades, también que, empoderando a la persona con discapacidad, como a sus líderes y a sus instituciones, se consigue el empoderamiento de toda la sociedad. La mayoría de las autoridades no fomentan políticas públicas de empoderamiento, autoestima y liderazgo de las personas con discapacidad, por falta de voluntad política y falta de empatía.

En cuanto a calidad de vida, se valora los funcionamientos y capacidades propias del fuero interno de una persona, no tiene que ver primordialmente con ingresos o acciones secundarias (Sen, 1987). Las personas entrevistadas refieren que viven, comen, pasean, duermen, etc. es decir, que su calidad de vida en una pequeña parte está bien en cuanto a algunos funcionamientos, pero, mientras haya inaccesibilidad física, de comunicación, transporte y otros, no pueden realizar funcionamientos más relevantes en cuanto a ser felices, tener autorrespeto, y participar activamente en la sociedad.

\section{Conclusiones}

La teoría del modelo social de discapacidad, se inició a fines de los sesenta; el concepto de inclusión social se inicia a comienzos de los años setenta, en respuesta a la exclusión social que había en esos tiempos de minorías étnicas, culturales y religiosas. Poco tiempo después, este concepto de inclusión social es aplicado a la persona con discapacidad, por la marginación y discriminación hacia ellos, a fin, de aceptarlos en la sociedad, pero, como se sabe, transcurridas varias décadas después, no se consigue aún en el Perú. 
Actualmente, gracias a la Convención sobre los derechos de las personas con discapacidad basada en los derechos humanos y el modelo social de discapacidad se les reconoce como sujetos de derechos, correspondiendo ubicar sus problemas fuera de ellos. No es que el modelo social es algo mágico que solucionará la problemática de la discapacidad como con una varita, pero es el inicio para que las autoridades y la sociedad en general replanteen el tratamiento y la forma de desarrollar a las personas con discapacidad, quitándoles a ellos todo obstáculo y propiciando fuertemente la igualdad de oportunidades en toda área de la sociedad. Una muestra de lo relegados que se está en nuestro país en este tema, es que en EEUU y países europeos el modelo social de discapacidad ha sido desarrollado casi en su totalidad, por lo que algunos estudiosos del tema inclusive dicen que ya no es relevante en su país.

Las barreras de actitud, las barreras físicas, las barreras sociales y las barreras políticas, aún persisten en la sociedad en el Callao y en las autoridades del distrito, esta situación hace que los derechos humanos de la persona con alguna discapacidad sigan siendo vulnerados; la sociedad y las autoridades vienen tratando la problemática de la discapacidad como pueden o como creen que deben hacer, no hay un conocimiento real, ni un instrumento que articule, organice y estructure todos los esfuerzos en una sola dirección (modelo social), y culmine en una meta; el desarrollo de la persona con discapacidad a través del empoderamiento, autoestima y liderazgo que permitirá lograr una mejor calidad de vida. En este sentido las personas con discapacidad pueden ayudar y orientar a dar soluciones concretas a sus problemas.

El Estado por medio de las Omaped, Oredis y Conadis tiene la oportunidad de evaluar y enmendar las políticas públicas que viene realizando. El modelo social de discapacidad influye directamente en el desarrollo de las personas, y es factible de materializase a través de las políticas públicas. Los funcionarios del Estado y la sociedad en general tienen que tomar conciencia y ser sensibilizados, deben de saber 
Modelo social como alternativa para el desarrollo de la persona con discapacidad, Callao. Perú

que las instituciones eficientes logran el desarrollo de las personas y cambian la calidad de vida de las personas.

\section{Referencias Bibliográficas}

Abberley, Paul (1987). Concepto de opresión y el desarrollo de una teoría social de la discapacidad. Revista Discapacidad y Sociedad, Volumen 2, Nro. 1. Inglaterra. (Pp. 5 - 19).

Aguado, Antonio (1995). Historia de las deficiencias. Editorial Fundación Once. España.

Alonso, Fernando (2016). La accesibilidad en evolución: La adaptación personaentorno y su aplicación al medio residencial en España y Europa. Tesis doctoral. Doctorado en relaciones internacionales e integración europea. España.

Álvarez, Gloria (2009). El régimen jurídico público de la discapacidad. Tesis doctoral. Doctorado en Derecho. Universidad Complutense de Madrid, España.

Booth, Tony y Ainscow, Mel (2011). Guía para la educación inclusiva: desarrollando el aprendizaje y la participación en los centros escolares. Organización de Estados Iberoamericanos para la educación, la ciencia y la cultura (OEI) y Fundación Benéfico - Social Hogar del Empleado (FUHEM). España.

Borrell i Carrió, Francesc (2002). El modelo biopsicosocial en evolución. Revista Elsevier. Volumen 119. Número 5. España. (Pp. 175 - 179).

Centro para el Control y la prevención de Enfermedades. CDC (2017). Las discapacidades y la salud. Disponible en:

https://www.cdc.gov/ncbddd/spanish/disabilityandhealth/disabilitybarriers.html. Consulta 04/10/2017

Chan, Margaret (2011). Primer Informe Mundial sobre discapacidad. ONU. EE.UU. Cohaila, Edwin (2015). La construcción de la confianza en las instituciones políticas: el caso de los distritos de San Martín de Porres y los Olivos. Tesis doctoral. Doctorado en Sociología. Pontificia Universidad Católica. Perú.

Congreso de la República del Perú (1998). Ley General de la Persona con discapacidad 27050. Diario oficial El Peruano 168310. Perú.

Congreso de la República del Perú (2012). Ley General de la Persona con discapacidad 29973. Diario oficial El Peruano 482000. Perú.

Del Águila, Luis (2011). Análisis y Evaluación del Plan de Igualdad de Oportunidades para las Personas con Discapacidad. Aportes de la Gerencia Social para mejorar las Políticas de discapacidad en el Perú. Tesis magistral. Maestría en Gerencia social. Pontificia Universidad Católica. Perú. 
Instituto Nacional de Estadística e Informática INEI (2014). I Encuesta Nacional Especializada sobre Discapacidad 2012. Disponible en: http://www.inei.gob.pe/media/MenuRecursivo/publicaciones_digitales/Est/Li b1171/ENEDIS\%202012\%20-\%20COMPLETO.pdf Consulta 29/05/2018

Laham, Mirta (2017). El modelo biopsicosocial. Disponible en: http://www.psicologiadelasalud.com.ar/art-comunidad//el-modelobiopsicosocial-154.html?p=1p. Consulta 15/07/2019

Maldonado, Jorge (2013). El modelo social de la discapacidad: Una cuestión de Derechos Humanos. Revista de Derecho UNED. Número 12. España. (Pp. $817-833)$.

Misari, David (2013). Teoría general del derecho. Ediciones Asociación Peruana de Ciencias y Conciliación APECC. Perú.

Ñaupas Humberto, Mejía Elías, Novoa Eliana y Villagómez Alberto (2014).

Metodología de la investigación. Cuantitativa - cualitativa y redacción de tesis. Universidad de Bogotá. Colombia.

Oliver, Mike (1998). Discapacidad y sociedad. Editorial Morata. España.

Organización de las Naciones Unidas ONU (2006). Convención sobre los derechos de las personas con discapacidad CDPD. Disponible en:

https://www.un.org/development/desa/disabilities-es/convencion-sobre-losderechos-de-las-personas-con-discapacidad-2.html

Consulta 19/05/2018.

Organización de las Naciones Unidas para la Educación, la Ciencia y la Cultura, Organización Internacional del Trabajo, y la Organización Mundial de la Salud. Unesco, OIT y OMS (2005). Estrategia para la rehabilitación, la igualdad de oportunidades, la reducción de la pobreza y la integración social de las personas con discapacidad. Disponible en;

https://apps.who.int/iris/bitstream/handle/10665/43126/9243592386_spa.pdf? sequence $=1$. Consulta 17/03/2018

Organización de las Naciones Unidas ONU (2009). Desarrollo de capacidades. Texto básico del PNUD. Disponible en:

https://www.undp.org/content/dam/undp/library/capacitydevelopment/spanish/Capacity_Development_A_UNDP_Primer_Spanish.pdf .Consulta 15/03/2018

Organización de las Naciones Unidas ONU (2015). Declaración Universal de Derechos Humanos. Disponible en:

https://www.un.org/es/documents/udhr/UDHR_booklet_SP_web.pdf Consulta 15/03/2018

Organización Mundial de la Salud OMS (2001). Clasificación internacional de funcionamiento de la discapacidad y la salud (CIF). Disponible en: 
Modelo social como alternativa para el desarrollo de la persona con discapacidad, Callao. Perú

https://aspace.org/assets/uploads/publicaciones/e74e4-cif_2001.pdf Consulta $19 / 05 / 2018$

Organización Mundial de la Salud OMS (2011). Resumen, Informe mundial sobre la discapacidad. Disponible en:

https://www.who.int/disabilities/world_report/2011/summary_es.pdf?ua=1

Consulta 17/06/2018

Orth, Ulrich y Robins, Richard (2014). El desarrollo de la autoestima. Corriente. Direcciones en ciencia psicológica. Número 23. EE.UU. (Pp. 381-387).

Otano, Guillermo (2015). Desarrollo humano y cambio social: Una crítica constructiva del enfoque de capacidad de Amartya $K$. Sen desde la sociología. Tesis doctoral. Doctorado en Sociología. Universidad de Navarra, Pamplona. España.

Padilla-Muñoz, Andrea (2010). Discapacidad: Contexto, concepto y modelos. International Law: Revista colombiana de derecho internacional. Número 16. Colombia. (Pp. 381-414).

Palacios, Agustina (2008). El modelo social de discapacidad: orígenes, caracterización y plasmación en la Convención Internacional sobre los derechos de las personas con discapacidad. Cinca. España.

Palacios, Agustina y Romañach, Javier (2006). El modelo de la diversidad, la bioética y los derechos humanos como herramientas para alcanzar la plena dignidad en la diversidad funcional. Ediciones Diversitas. España.

Patston, Philip (2007). Diversidad funcional constructiva: Un nuevo paradigma más allá de la discapacidad y deterioro. Revista Discapacidad y rehabilitación. Volumen 19. Nro. 20-21. EEUU (Pp. 1625-1633).

Priestly, Mark (1998). Construcciones y creaciones: idealismo, materialismo y teoría de la discapacidad. Revista Discapacidad y Sociedad. Volumen 13, Edición 1. Reino Unido. (Pp. 75 - 94).

Protágoras, Georgias (1998). Carta Séptima. Introducción, traducción y notas de Javier Martínez García. Editora Alianza. España.

Rueda, Julián (2013). El desarrollo de capacidades. Un enfoque central de la cooperación al desarrollo. Ediciones Universidad de Barcelona. España.

Sánchez, Dalia; Romero Rosalinda y Padrón José (2019). Inclusión de personas con discapacidades auditivas y visuales en la investigación. Revista Telos. Revista de estudios interdisciplinarios en ciencias sociales. Volumen 21. Número1. Venezuela. (Pp. 221 - 241).

Sánchez, Jairo (2015). La transformación del contexto escolar hacia la educación inclusiva. Tesis doctoral. Doctorado en Educación. Universidad Autónoma de Madrid. España.

Schalock, Robert y Verdugo, Miguel (2007). El concepto de calidad de vida en los servicios y apoyos para personas con discapacidad intelectual. Revista 
española sobre discapacidad intelectual. Volumen 38. Número 224. España. (Pp. 21 - 36).

Seligman, Martín (2000). Psicología positiva, prevención positiva y terapia positiva. Manual de psicología positiva. Ediciones Snyder y López. EEUU.

Senge, Peter (1990). La Quinta Disciplina. Granica. Argentina.

Tizón, Jorge (2007). A propósito del modelo biopsicosocial, 28 años después: epistemología, política, emociones y contratransferencia. Revista Elsevier. Volumen 39. Número 2. España. (Pp. 93 - 97).

Sen, Amartya (1987). El estándar de vida. University Press Cambridge Inglaterra.

Venturiello, María Pía (2017). Discapacidad en contexto: origen social y responsabilidad colectiva. Revista Bordes. Revista de Derecho, Política y Sociedad. Disponible en:

http://revistabordes.com.ar/discapacidad-en-contexto-origen-social-yresponsabilidad-colectiva/\#. Consulta 28/04/2017.

Villela, Fabiola y Linares, Jorge (2011). Eugenesia. Un análisis histórico y una posible propuesta. Revista Acta Bioethica. Volumen 17. Número 2. México. (Pp. 189-197). 